\title{
A rare cause of nephrotic syndrome in a 14-year-old boy: Questions
}

\author{
Hulya Nalcacioglu • Demet Tekcan • Gurkan Genc • \\ Atakan Comba • Bilge Can Meydan • Gonul Caltepe • \\ Ozan Ozkaya • Ayhan Gazi Kalayci
}

Received: 11 July 2012 /Revised: 12 July 2012 / Accepted: 12 July 2012 / Published online: 24 August 2012

(C) IPNA 2012

Keywords Nephrotic Syndrome · Child · Cystic mass

\section{Case summary}

A previously healthy 14 -year-old boy was presented with a 10-day history of progressive periorbital and bilateral lower extremity edema. He also noted that the frequency and amount of his urine had decreased. He had no gross hematuria, no recent sore throat, or upper respiratory tract infections. His medical history was unremarkable, with no known history of kidney disease.

Physical examination on admission was unremarkable except for moderate edema on bilateral eyelids and lower extremities. His cardiovascular, respiratory, neurological, and genitourinary exams were all normal.

Blood pressure was 130/80 mmHg. His height was $151 \mathrm{~cm}$ (25-50 p) and weight was $44.5 \mathrm{~kg}$. Laboratory findings revealed that he had marked hypoalbuminemia $(2.1 \mathrm{~g} / \mathrm{dl})$ with heavy proteinuria (5167 mg/dl, or $20 \mathrm{mg} / \mathrm{mg}$ creatinine) and microscopic hematuria (ten red blood cells/HPF with no red blood cell

The answers to these questions can be found at http://dx.doi.org/ 10.1007/s00467-012-2284-8.

H. Nalcacioglu $(\varangle) \cdot$ D. Tekcan $\cdot$ G. Genc $\cdot$ O. Ozkaya

Pediatric Nephrology Department,

Ondokuz Mayis University Faculty of Medicine,

Kurupelit,

Samsun, Turkey

e-mail: hulyanalcacoglu@hotmail.com

A. Comba · G. Caltepe · A. G. Kalayci

Pediatric Gastroenterology, Hepatology and Nutrition Department,

Ondokuz Mayis University Faculty of Medicine,

Samsun, Turkey

B. Can Meydan

Pathology Department,

Ondokuz Mayis University Faculty of Medicine,

Samsun, Turkey casts). Hyperlipidemia (T-Chol $225 \mathrm{mg} / \mathrm{dl}$, TG $263 \mathrm{mg} / \mathrm{dl}$ ) was also noted. Serum complements were normal (C3 $0.8 \mathrm{~g} / \mathrm{L}, \mathrm{C} 40$. $4 \mathrm{~g} / \mathrm{L}$ ), and anti-nuclear antibody was negative. Renal function was intact (creatinine $0.7 \mathrm{mg} / \mathrm{dl}$, BUN $20 \mathrm{mg} / \mathrm{dl}$ ). HBs antigen, HCV antibody, and human immunodeficiency virus (HIV) were all negative. There was no evidence of streptococcal infection. Based on his clinical and laboratory findings, he was diagnosed as having nephrotic syndrome. The patient was hospitalized and investigated for the etiology of the nephrotic syndrome. During the work-up for a renal biopsy, a cystic mass in the right upper abdomen was found by ultrasonography and confirmed by computed tomography (CT) scan (Fig. 1).

\section{Questions}

1. What is the most likely diagnosis of the cystic mass?

2. What additional tests would you obtain to confirm the diagnosis?

3. How should this patient be managed?

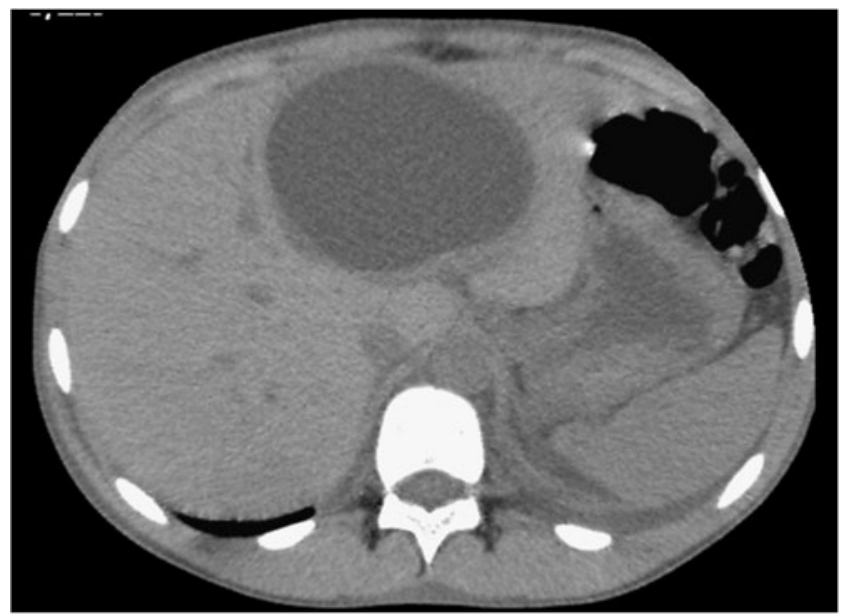

Fig. 1 Computed tomography scan of the abdomen showing cystic lesion in the left lobe of the liver 